\title{
L'héritage byzantin de l'Europe : un recueil rare de photographies anciennes sur la Bulgarie
}

\section{Catherine Vanderheyde}

\section{(2) OpenEdition \\ 1 Journals}

Édition électronique

URL : http://journals.openedition.org/rbnu/651

DOI : $10.4000 /$ rbnu. 651

ISSN : 2679-6104

Éditeur

Bibliothèque nationale et universitaire de Strasbourg

\section{Édition imprimée}

Date de publication : 1 novembre 2017

Pagination : 20-23

ISBN : 9782859230678

ISSN : 2109-2761

\section{Référence électronique}

Catherine Vanderheyde, «L'héritage byzantin de l'Europe : un recueil rare de photographies anciennes sur la Bulgarie », La Revue de la BNU [En ligne], 16 | 2017, mis en ligne le 01 juillet 2019, consulté le 11 décembre 2020. URL : http://journals.openedition.org/rbnu/651; DOI : https://doi.org/10.4000/rbnu. 651

\section{cc) (1) (2)}

La Revue de la BNU est mise à disposition selon les termes de la Licence Creative Commons Attribution - Pas d'Utilisation Commerciale - Partage dans les Mêmes Conditions 4.0 International. 


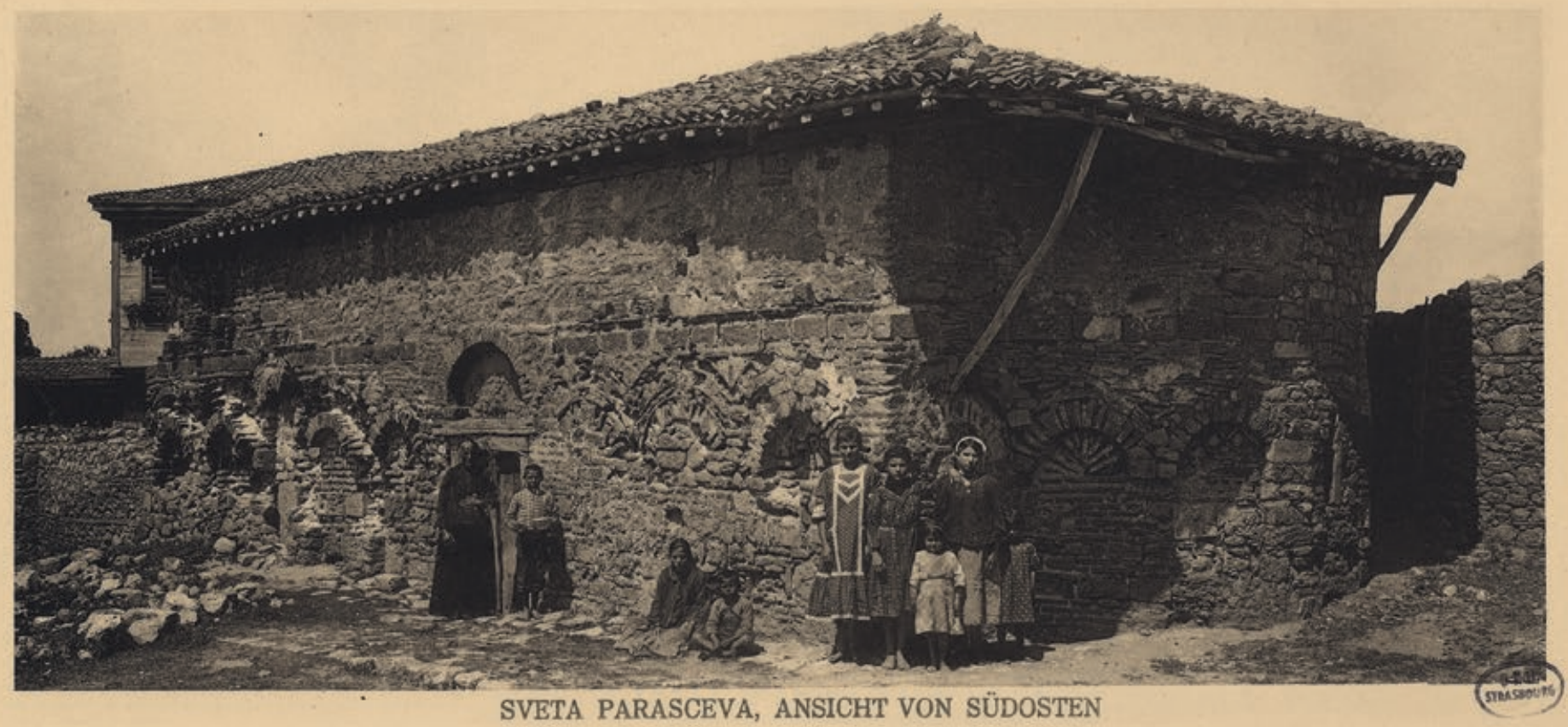

Alte Bauten in Bulgarien /

hrsg. von Cornelius Gurlitt, Berlin, [s. n.], [1916] 


\section{BULGARIE \\ L'HÉRITAGE BYZANTIN DE L'EUROPE : UN RECUEIL RARE DE PHOTOGRAPHIES ANCIENNES SUR LA BULGARIE}

PAR CATHERINE VANDERHEYDE

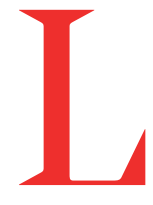

a Bibliothèque nationale et universitaire de Strasbourg conserve un précieux ouvrage intitulé Alte Bauten in Bulgarien (Monuments anciens de Bulgarie), publié à Berlin en 1916. L'auteur, Max Zimmermann (1881-1962), avait soutenu sa thèse de doctorat en 1911 à l'École d'architecture de l'Université technique de Dresde. Ses compétences furent certainement remarquées par l'éditeur de ce beau livre, Cornelius Gurlitt (1850-1938), lui-même architecte et historien de l'art, qui aimait s'adonner à l'écriture comme l'atteste le nombre de ses monographies. Il avait commencé sa carrière en 1899 en tant que professeur à l'Université technique de Dresde, où il fut élu recteur en 1904/1905. L'ouvrage qu'il a édité sur les Monuments anciens de Bulgarie se présente comme un portfolio contenant relativement peu de texte en regard des nombreux dessins architecturaux et photographies en noir et blanc. Divers édifices religieux situés à plusieurs endroits de la Bulgarie, tels Messemvria (actuelle Nessebar), Batchkovo, Arbanassi et Véliko Tarnovo, y sont magnifiquement illustrés. Cela lui confère une indéniable valeur pour l'étude de l'architecture médiévale bulgare.
Ce sont les églises de Messemvria qui sont les plus largement mises en valeur : l'auteur fournit en effet plusieurs vues, relevés, restitutions et plans architecturaux des sept édifices religieux les mieux conservés de la ville. Un plan topographique schématique donne leur localisation sur cette presqu'île rocheuse. Reliée au continent par un isthme de $400 \mathrm{~m}$ de long, elle conserve aujourd'hui encore un patrimoine archéologique et architectural exceptionnel, même si ses côtes ont été peu à peu grignotées par la mer Noire. Sa superficie devait en effet atteindre environ 40 hectares au $2^{\mathrm{e}}$ millénaire avant J.-C., comme l'ont montré les fouilles archéologiques sousmarines. La ville prend son essor lorsqu'une colonie de Grecs doriens venus de Mégare s'y installe au $6^{\mathrm{e}}$ siècle avant J.-C. L'aménagement de deux ports, au nord et au sud de la presqu'île, assure alors à Messemvria, désormais fortifiée, un développement commercial et culturel important, impliquant des échanges avec l'ensemble du monde grec antique. Depuis le milieu du $5^{\mathrm{e}}$ siècle jusqu'au $2^{\mathrm{e}}$ siècle avant J.-C., la cité frappera des monnaies d'or, d'argent et de bronze. Cette ville grecque prospère sera intégrée à l'empire romain au $1^{\text {er }}$ s. av. J.-C., puis à l'empire 
byzantin à partir du $4^{\text {e }}$ siècle ap. J.-C. Plusieurs temples antiques sont alors transformés en églises, comme par exemple le sanctuaire dédié à Hercule auquel succéda l'église des Saints-Apôtres, ou encore le temple de Zeus Hyperdexios situé sur l'ancienne agora où s'élève aujourd'hui l'église Sainte-Sophie, connue aussi sous le nom d'« ancienne Métropole ». La ville continue à se couvrir d'édifices religieux au cours de la période médiévale, lorsque Byzantins et Bulgares s'en disputent la souveraineté. Dans son introduction sur Messemvria, Max Zimmermann compare non sans lyrisme cette presqu'île à celle du mont Athos, ce qui est excessif car sa superficie est bien moindre et le lieu, dépourvu de toute montagne, ne fut jamais exclusivement voué au monachisme. Néanmoins, elle connut une période d'opulence aux $13^{\mathrm{e}}$ et $14^{\mathrm{e}}$ siècles, comme en témoignent encore les belles églises du Christ Pantokrator, des archanges Michel et Gabriel, de Sainte-Paraskevi, de Saint-Théodore et de Saint-Jean Aliturgitos. Celles-ci présentent de nombreux points communs avec les églises byzantines à coupoles de la même période, caractérisées par des façades animées de niches aveugles et incrustées d'éléments colorés.

L'occupation de la ville par les Ottomans à partir de 1396 ne mit pas un terme à l'activité de construction, mais celle-ci se réduisit progressivement jusqu'au début du $20^{\mathrm{e}}$ siècle. Peuplée essentiellement de grécophones, Messemvria fut intégrée à la province de Roumélie orientale en 1878 suite au traité de Berlin. Elle était alors gouvernée par un représentant civil et un responsable militaire orthodoxes et jouissait, comme l'ensemble de la province, d'une autonomie administrative vis-à-vis du pouvoir ottoman. Cette dernière fut de courte durée puisqu'en 1885, son territoire fut rattaché à la Bulgarie. La naissance de la principauté bulgare en 1908, qui deviendra l'alliée politique de l'Allemagne jusqu'en 1944, a certainement encouragé la réalisation du précieux livre de Max Zimmermann. Celui-ci présente une grande valeur documentaire et propose d'intéressantes restitutions d'édifices en ruines, tel celui de Saint-Jean Aliturgitos. Les informations et les documents contenus dans l'ouvrage, sans précédent, furent très vite exploités mais aussi contestés par l'architecte Alexander Rachenov. Celui-ci publia en 1932 un livre intitulé Églises de Mesemvria, dans la nouvelle et luxueuse collection des
Monuments de l'art en Bulgarie soutenue par l'Institut archéologique bulgare. Dans le chapitre de ce livre consacré à l'église Sainte-Paraskevi (celle-là même reproduite ici), l'auteur exprime ainsi son désaccord avec l'hypothèse de Max Zimmermann au sujet de l'élévation de cet édifice, arguant que le savant allemand n'avait pas remarqué qu'un escalier conduisait à l'étage supérieur du narthex. Selon A. Rachenov, cet escalier impliquait l'existence d'une tour-clocher, tandis que la nef devait être surmontée d'une coupole.

La photographie de l'église dédiée à sainte Paraskevi que l'on peut admirer dans le livre de Max Zimmermann est néanmoins éloquente à plus d'un titre. Elle nous montre un édifice en mauvais état, dont la forme rectangulaire et le toit de tuiles à double pente évoquent davantage une maison qu'une église. Devant sa façade, on reconnaît une vieille femme modestement vêtue, accompagnée d'un jeune garçon tenant un morceau de pain et un bol. À côté d'eux, une adolescente et deux enfants sont assis par terre. À leur gauche, un groupe de filles de divers âges posent pour la photo. Tous les enfants sont pieds nus et ont un visage sérieux qui exprime autant l'étonnement que la curiosité. Cette vue illustre bien les propos de l'auteur qui rapporte que, lors de sa visite, Messemvria était devenue une petite ville sévèrement affectée par la pauvreté, où vivaient seulement 1000 habitants. Si l'on compare ce document avec une vue de la même église prise au printemps 2007 (voir ill. ci-contre), le contraste est saisissant : les restaurations effectuées depuis la parution du livre de Zimmermann ont permis une reconstitution partielle de l'aspect initial de cet édifice. Si la coupole qui couvrait l'église originale n'a pas été reconstruite, la façade multicolore, animée par une série de niches aveugles et décorée de céramiques vernissées, donne une bonne idée de l'aspect extérieur que devait offrir ce bâtiment aux époques médiévale et moderne. Plus généralement, la mise en valeur de cette église témoigne de l'attachement que manifeste la Bulgarie envers les monuments anciens érigés sur son territoire. Messemvria, classée au patrimoine mondial de l'UNESCO depuis 1983, est un exemple très réussi de cet engagement, qui rappelle l'héritage byzantin de l'Europe. 


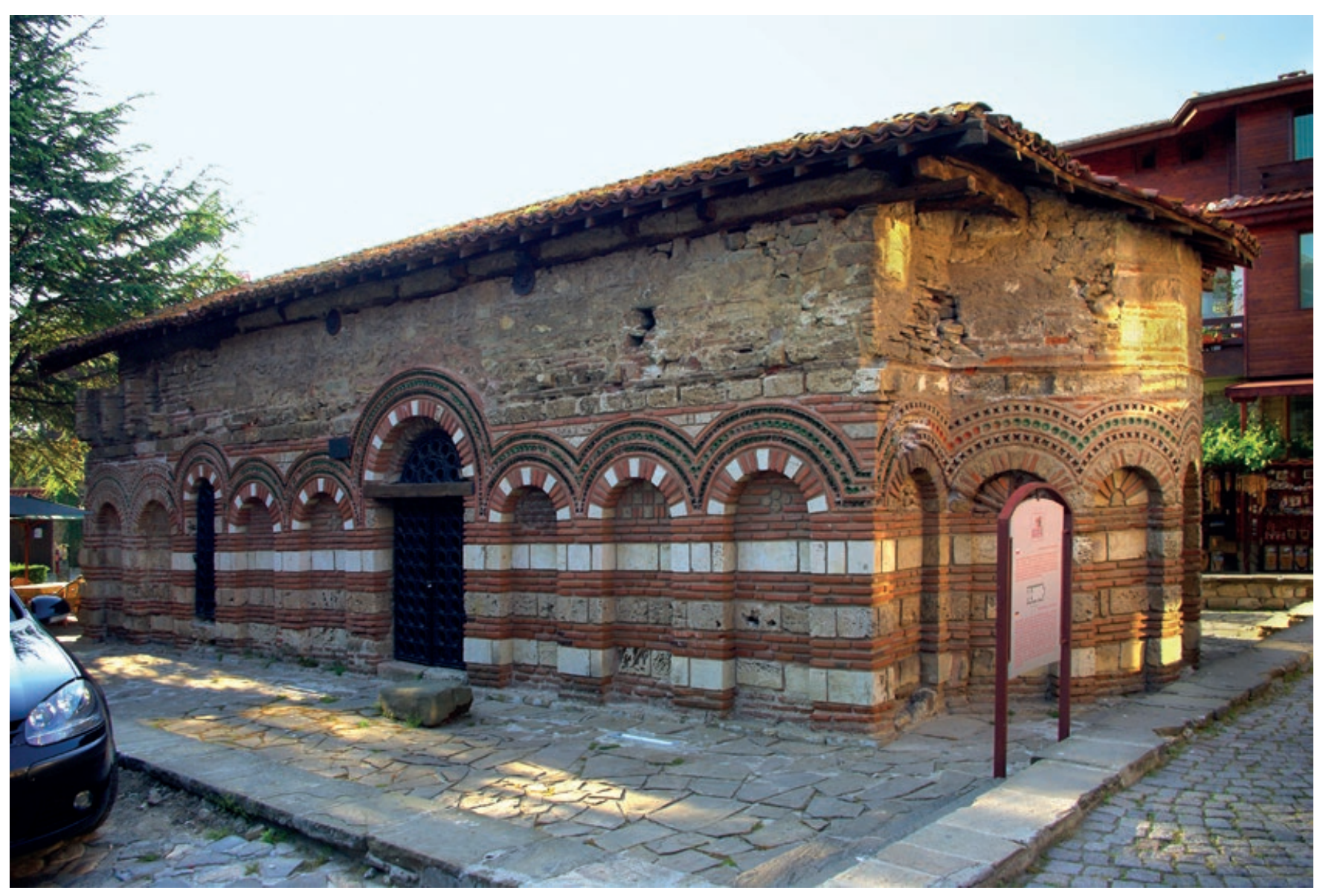

L'église Sainte-Paraskevi en 2007 